\title{
Comparison of different induction dosing of CD3+ cell count based anti-thymocyte globulin for deceased donor kidney transplantation: single center experience
}

\author{
Joon Seok Oh, Joong Kyung Kim, Dong Yeol Lee, Hee Yeon Kim
}

Division of Nephrology, Department of Internal Medicine, Bongseng Memorial Hospital, Busan, Korea

Background: The rabbit anti-thymocyte globulin (ATG) is the most widely used lymphocyte depleting agent in renal transplantation. This can be expected to have a profound immune inducing effect, but it has been not widely used in Korea due to concerns about side effects such as leukopenia, thrombocytopenia, and infection. This has made it necessary to find the minimum dosing to show adequate immunosuppressive effects. So, we compared the clinical features of CD3+ cell count based ATG use with a cumulative dose of $3 \mathrm{mg} / \mathrm{kg}$ and $4 \mathrm{mg} / \mathrm{kg}$ as an induction immunosuppressant.

Methods: Fifty-one patients have received deceased donor kidney transplantation with ATG induction therapy in Bongseng Memorial Hospital from 2013 to 2020 . And they were divided into two groups: patients who treated with cumulative dose $3.0 \mathrm{mg} / \mathrm{kg}$ of ATG (group A) and $4.0 \mathrm{mg} / \mathrm{kg}$ (group B). We compared patient's survival and graft's survival in both groups. The data were collected regarding recipients' panel reactive antibody, CD3+ lymphocyte count, immunosuppressant, viral infection, acute rejection, and adverse events.

Results: The demographic characteristics of the two groups were comparable. The incidence of delayed graft function was statistically significantly lower in the cumulative dose $4 \mathrm{mg} / \mathrm{kg}$ group. There was no statistically significant difference in the graft's survival and serum creatinine between the two groups, but it was slightly better in $4 \mathrm{mg} / \mathrm{kg}$ group. The incidence rates of acute rejection and infectious events as cytomegalovirus disease or urinary tract infection were not significantly different between the two groups. CD3+ lymphocyte count was statistically significantly decreased until 6 months after transplantation in both groups compared to before transplantation.

Conclusions: We suggest that ATG induction with cumulative dose of $4 \mathrm{mg} / \mathrm{kg}$ would be safe and effective for deceased donor kidney transplantation in Korea.

Corresponding author: Joon Seok Oh

E-mail: j-seok@hanmail.net

(C) The Korean Society for Transplantation

This is an Open Access article distributed under the terms of the Creative Commons Attribution Non-Commercial License (http://creativecommons.org/licenses/by-nc/4.0/) which permits unrestricted non-commercial use, distribution, and reproduction in any medium, provided the original work is properly cited. 